\title{
Ambient and fire behaviour of eccentrically loaded elliptical slender concrete-filled tubular columns
}

\author{
A. Espinos ${ }^{\text {a }}$, M. L. Romero ${ }^{\text {**, J.M. Portolés }}{ }^{\mathrm{b}}$, A. Hospitaler ${ }^{\mathrm{a}}$ \\ ${ }^{a}$ Instituto de Ciencia y Tecnología del Hormigón (ICITECH), \\ Universitat Politècnica de València, Valencia, Spain \\ ${ }^{b}$ Department of Mechanical Engineering and Construction, \\ Universitat Jaume I, Castellón, Spain \\ *Corresponding author. e-mail address: mromero@mes.upv.es
}

\begin{abstract}
This paper presents the results of an experimental program carried out on slender elliptical hollow section columns filled with concrete. Given the reduced number of experimental results found in the literature on concrete filled tubular columns with elliptical cross-section, the main objective of this paper is to compare the behaviour of such innovative cross-sections under ambient and high temperatures. The test parameters covered in this experimental program were the load eccentricity $(0,20$ and $50 \mathrm{~mm})$ and the type of infill (plain concrete or bar-reinforced concrete). Six room temperature tests were performed, while other six tests were carried out at elevated temperatures, under both concentric and eccentric axial load. Using the results of these tests, the current provisions of Eurocode 4 for room temperature and fire design were assessed, and a specific design proposal developed by the authors was evaluated.
\end{abstract}

Keywords: Fire resistance; Concrete filled tubular columns; Eurocode 4; Simple calculation model; Reinforcement; Eccentricity; Elliptical hollow sections 


\section{NOTATION}

$A_{i} \quad$ Cross-sectional area of the of the part $i$ of the composite section

$A_{s n}$

Area of the reinforcing bars within the region of depth $h_{n}$

$A_{m} / V$

$a$

$b$

CFEHS

CFT

e

$E_{a, \theta}$

$E_{c, s e c, \theta}$

$E_{s, \theta}$

$(E I)_{f i, e f f}$

EC4

EHS

$f_{\mathrm{c}}$

$f_{\mathrm{s}}$

$f_{\mathrm{y}}$

$h_{n}$

$I_{i, \theta}$

$N_{u}$
Section factor

Half larger outer dimension of an elliptical section

Half smaller outer dimension of an elliptical section

Concrete filled elliptical hollow section

Concrete filled tube

Load eccentricity

Modulus of elasticity of structural steel at the temperature $\theta$

Secant modulus of concrete at the temperature $\theta$

Modulus of elasticity of reinforcing steel at the temperature $\theta$

Effective flexural stiffness in the fire situation

Eurocode 4

Elliptical hollow section

Compressive cylinder strength of concrete at room temperature (test date)

Yield strength of reinforcing steel at room temperature

Yield strength of structural steel at room temperature

Distance of the neutral axis to the centre-line of the cross-section

Second moment of area of the part $i$ of the cross-section at the temperature $\theta$

Buckling length of the column in the fire situation

Test load

Design axial buckling load in the fire situation

Ultimate axial load at room temperature

Perimeter of the section

Fire resistance time

Steel tube wall thickness

Column length

Plastic section modulus of steel

Plastic section modulus of concrete

Plastic section modulus of the reinforcing bars

Plastic section modulus of the steel region of depth $2 h_{n}$

Plastic section modulus of the concrete region of depth $2 h_{n}$

Plastic section modulus of the reinforcing bars within the region of depth $2 h_{n}$ 
$\varphi_{i, \theta} \quad$ Reduction coefficient depending on the effect of thermal stresses

$\varphi_{s} \quad$ Reduction coefficient depending on the percentage of reinforcement

$\varphi \delta \quad$ Reduction coefficient depending on the eccentricity

$\mu=N / N_{u} \quad$ Axial load level

$\bar{\lambda} \quad$ Relative slenderness at room temperature

$\bar{\lambda}=\sqrt{N_{p l} / N_{c r}}=\sqrt{\left(A_{c} f_{c}+A_{a} f_{y}+A_{s} f_{s}\right) /\left[\left(\pi^{2} E I\right) / L^{2}\right]}$

$\theta_{i, e q} \quad$ Equivalent temperature of the part $i$ of the cross-section

\section{INTRODUCTION}

The structural behaviour of elliptical hollow sections (EHS) has been deeply studied in recent years by Gardner and co-workers, covering cross-section classification [1] and the evaluation of the response in compression [2], shear [3], bending [4] and flexural buckling [5]. Furthermore, the elastic buckling response of elliptical hollow sections in compression was studied by Ruiz-Teran and Gardner [6] and Silvestre [7]. A review article was published by Chan et al. [8] on the structural design of EHS, which brought together the previous developments. In a more recent work, Gardner et al. [9] studied the structural behaviour of EHS under combined compression and uniaxial bending. Additionally, Law and Gardner [10] investigated the lateral instability of EHS members in bending.

The effect of filling EHS columns with concrete was examined by Yang et al. [11] and Zhao and Packer [12], through testing stub columns under compressive axial load at room temperature. Also concrete filled stainless steel elliptical stub columns were experimentally investigated by Lam et al. [13].

Dai and Lam [14] developed a numerical model to represent the axial compressive behaviour of elliptical concrete filled steel tubular stub columns. These authors studied the differences in the degree of concrete confinement between circular and elliptical hollow sections, observing that the circular sections provided higher confinement than the elliptical 
shapes, due to the different contact stress distribution around the perimeter of the section. Based on this study, Dai and Lam [14] developed a stress-strain model for concrete confined by elliptical steel hollow sections.

Recently, Sheehan et al. [15] examined the structural response of concrete filled elliptical hollow section (CFEHS) stub columns under eccentric compression through both experimental and numerical studies. Analytical compression-bending moment interaction curves were derived from the results of this investigation.

Jamaluddin et al. [16] presented the results of a series of experiments on elliptical concrete filled tubular (CFT) columns subjected to axial compressive load. In this experimental program, a total of twenty-six specimens were tested, including both stub and slender columns.

Considering the reduced number of experimental results available on CFEHS columns, new experiments are presented in this paper. Differently from previous experimental studies, this paper focuses on slender columns subjected to eccentric loads. The test results are used as a basis to evaluate the current design rules in EN 1994-1-1 [17] for CFT columns.

Regarding the fire response of elliptical columns, the number of investigations is very limited. Some recent work on unfilled EHS columns subjected to fire carried out by Scullion et al. [18][19][20] can be found in the literature, but no experimental studies have been carried out so far on elliptical concrete filled steel tubular columns exposed to fire. The only work developed in this field can be found in previous numerical investigations from the authors [21] and the studies from Dai and Lam [22], who discussed the effect of the sectional shape on the structural fire behaviour of axially loaded CFT stub columns, showing that the best fire performance is obtained with circular sections, followed by columns with elliptical, square and rectangular sections. It is worth noting that no experimental studies on slender CFEHS 
columns at elevated temperatures have been presented yet, nor any design method for the calculation of the fire resistance of these composite columns has been developed to date.

In previous work from the authors of this paper [21], a non-linear three-dimensional finite element model for CFEHS columns exposed to fire was presented. In the absence of fire tests on elliptical columns to validate the model, the values of the modelling parameters from a previously validated model for circular columns [23] were adopted. Based on the results of parametric studies, it was observed that, as expected, the fire resistance of the columns decreased with an increase in member slenderness and load level, as well as with an increase of the section factor. The existing design guidance in EN 1994-1-2 [24] for the calculation of the buckling resistance of CFT columns in fire was assessed. It was observed that neglecting the effect of thermal stresses (i.e. assuming flexural stiffness reduction coefficients equal to unity) led to unsafe results when applying the simple calculation model to slender CFEHS columns in axial compression. In the absence of specific guidance, it was recommended to use the flexural stiffness reduction coefficients from the French National Annex to EC4 [25] using an equivalent diameter of $D=P / \pi$. In more recent investigations [26] [27], the authors developed a specific method for calculating the design axial buckling load in the fire situation of bar-reinforced circular and elliptical CFT columns subjected to concentric axial load, based on the guidelines of Clause 4.3.5.1 in EN 1994-1-2 for the fire design of composite columns.

One of the aims of this paper is to support with experimental evidence the previous findings from the authors, and to serve as a basis for the development of future design rules for elliptical CFT columns both in fire and at room temperature. 


\section{EXPERIMENTAL STUDY ON CONCRETE FILLED ELLIPTICAL STEEL COLUMNS AT ROOM TEMPERATURE}

\subsection{General}

The authors have performed several experimental campaigns, [28] to [31], to study the buckling resistance at room temperature of slender CFST columns with circular, square and rectangular cross-sections. However, no tests can be found in the literature which study the influence of eccentricity in slender elliptical CFST columns, only Jamaluddin et al. [16] having investigated concentrically loaded columns of such typology.

The tests presented in this paper were designed for investigating the effects of two parameters on the behavior of slender elliptical CFST columns subjected to compressive axial load: type of infill (plain concrete or bar-reinforced concrete) and eccentricity $(e)$. In this experimental program, six CFEHS columns of cross-sectional dimensions $220 \times 110 \times 12 \mathrm{~mm}$ were tested at room temperature, under both concentric and eccentric loads, using eccentricities of 20 and $50 \mathrm{~mm}$. Three of the column specimens were unreinforced, while the other three made use of reinforcing bars. The dimensions of the typical cross-section of an unreinforced and a bar-reinforced column can be seen in Fig. 1.

All the column specimens had a buckling length of $2135 \mathrm{~mm}$ and were tested under pinned-pinned (P-P) end conditions on their minor axis. Plain and bar-reinforced C30 grade concrete was used in this experimental program. Table 1 summarizes the experimental data.

It can be observed in Table 1 that two slenderness can be defined, for buckling of the columns about their strong axis $\left(\overline{\lambda_{y}}\right)$ and weak axis $\left(\bar{\lambda}_{z}\right)$, which have been calculated as defined in Eurocode 4 (see notation section). All the specimens presented obviously a higher slenderness in their weak axis $\left(\overline{\lambda_{z}}>\overline{\lambda_{y}}\right)$, this slenderness being always higher than 0.5 . In order to avoid any interaction between the strong and weak axis, the eccentricities were 
applied in all cases about the weak axis. This interaction should be studied in a future research, where a larger number of tests must be performed.

\subsection{Column specimen and test setup}

All the specimens were manufactured at Universitat Politècnica de València (Spain) and tested later at Universitat Jaume I in Castellón (Spain). The buckling length of the columns was $2135 \mathrm{~mm}$ in all tests as, despite the steel tubes were cut with a length of $2000 \mathrm{~mm}$, the distance between the hinges of the loading frame required the addition of a special assembly with a length of $135 \mathrm{~mm}$.

A $300 \times 300 \times 15 \mathrm{~mm}$ steel plate was welded to the bottom end of the columns. The columns were then put in an upright position and filled with concrete, and afterwards shaken by means of an external vibrator in order to consolidate the concrete inside the steel tube. The columns were sealed with plastic at their top ends in order to avoid moisture leaks and left upright for 28 days. After concrete was cured, the top surface of the columns was polished producing a straight plane and a second end plate of the same dimensions $(300 \times 300 \times 15 \mathrm{~mm})$ was then welded to the top end of the columns.

All the specimens were tested in a $5000 \mathrm{kN}$ testing frame in a horizontal position, Fig. 2a, where the pinned ends were designed to apply the same eccentricity at both ends, with values of 0, 20 and $50 \mathrm{~mm}$. More details of the test setup can be found in [28] and [29]. Linear variable displacement transducers (LVDTs) were used to measure the deflection at five points along the column $(0.25 L, 0.375 L, 0.5 L, 0.625 L$ and $0.75 L)$.

Once the specimen was put in place, displacement control tests were carried out in order to measure post-peak behaviour. 


\subsection{Material properties}

Steel tubes

Cold formed elliptical steel hollow sections were used in the experimental program, with external dimensions $220 \times 110 \mathrm{~mm}$ and wall thickness of $12 \mathrm{~mm}$. The steel grade was $\mathrm{S} 355$, although the real yield strength of the hollow steel tubes $\left(f_{\mathrm{y}}\right)$ was obtained for each column specimen by performing the corresponding coupon test (see Table 1). It is worth noting that although the nominal yield strength of steel was the same for all the hollow sections (355 MPa), the actual yield strength was for all cases higher than the nominal value, with a wide scatter between the different specimens. The modulus of elasticity of steel was set following the European standards with a value of $210 \mathrm{GPa}$.

\section{Concrete}

In this experimental program, only one type of concrete was used, with nominal compressive strength of $30 \mathrm{MPa}$. The concrete batches were prepared in a planetary mixer.

In order to obtain the real compressive strength of concrete $\left(f_{\mathrm{c}}\right)$, sets of concrete cylinders were prepared and cured in standard conditions during 28 days. All samples were tested on the same day as the column was tested, as shown in Table 1.

Reinforcing bars

The reinforced specimens followed the arrangement presented in Fig. 1b, with four longitudinal reinforcing bars of $10 \mathrm{~mm}$ diameter and $6 \mathrm{~mm}$ stirrups with $30 \mathrm{~cm}$ spacing along the column length. The geometrical reinforcement ratio $\left(A_{\mathrm{s}} / A_{\mathrm{c}}\right)$ was equal to $2.37 \%$. The nominal yield strength of the reinforcing steel was $500 \mathrm{MPa}$, while the measured yield strength $\left(f_{\mathrm{s}}\right)$ is given in Table 1 . 


\subsection{Experimental results}

The maximum axial load of all specimens $\left(N_{\mathrm{u}}\right)$ is listed in Table 1 and the axial force versus mid-span displacement response for all tests is presented in Fig. 3, where the effect of the load eccentricity and the use of reinforcement are analyzed. The general trend of the curves results as expected: when the eccentricity increases the maximum load decreases. However, it must be highlighted the null effect of the reinforcing bars in the overall behavior of the columns. Only small differences are found due to the diverse values of the steel yield strength.

It is worth noting that the eccentricity was in all cases applied about the weak axis, all the columns having a high slenderness $\left(\overline{\lambda_{z}}\right)$, close to 0.8 . Consequently, it can be stated that the reinforcing bars do not contribute to improve the strength and stiffness of the columns when eccentricity is applied about the weak axis.

This result for elliptical CFST columns is not in line with the results achieved by the authors in a previous work [28] for circular CFST columns, where a noticeable difference was observed between bar-reinforced and unreinforced columns.

The unexpected behaviour of test E-00 (unreinforced) requires special consideration, as when it is compared against test RE-00 (bar-reinforced) in Fig. 3, the column specimen without reinforcement resisted a significantly higher axial load than the bar-reinforced column, despite having a lower steel strength $\left(f_{\mathrm{y}}=348 \mathrm{MPa}\right.$ for specimen E-00 versus $f_{\mathrm{y}}=$ $372 \mathrm{MPa}$ for specimen RE-00). This is due to an anomalous behaviour in test E-00. This test was conducted under a perfect concentric axial load measured with a laser. As the axial load was being increased during the experiment, the column experienced a change in its curvature. It started to curve upwards (against the self-weight), but suddenly, and close to the maximum load, it changed to curve downwards. This behaviour can be understood as if a negative eccentricity would have been applied to the column due to an initial imperfection. In order to 
avoid this effect in the subsequent RE-00 test, an initial positive eccentricity of $2 \mathrm{~mm}$ was applied to force the column to curve downwards, so as to avoid this behaviour.

Accordingly, the difference observed between these two tests is not reliable, although it is important to conclude that for concentric tests, small differences in the initial eccentricity can have a significant effect in the load-bearing capacity of the columns ( $12 \%$ difference between tests E-00 and RE-00). This result was also observed by the authors [28] for circular CFST columns, where the eccentricity due to bow imperfections became significant, presenting unstable behaviour in specific cases.

\section{EXPERIMENTAL STUDY ON CONCRETE FILLED ELLIPTICAL STEEL COLUMNS AT ELEVATED TEMPERATURE}

\subsection{General}

Despite a great number of fire tests can be found in the literature on CFT columns of circular and square section, the fire resistance of EHS columns filled with concrete has not yet been investigated through experimental testing.

In this experimental program, six CFEHS columns equivalent to those previously tested at room temperature were subjected to a fire test, under both concentric and eccentric loads, using eccentricities of 20 and $50 \mathrm{~mm}$. Again, three of the column specimens were unreinforced, while the other three were bar-reinforced.

As the height of the furnace was fixed, all the column specimens had a length of 3180 $\mathrm{mm}$ and were tested under pinned-fixed (P-F) end conditions. With these boundary conditions, the buckling length of the tests at room temperature and fire were approximately the same. The axial load applied to the columns was a $20 \%$ of their theoretical ultimate capacity at room temperature. Table 1 lists the main characteristics of the tested specimens. 


\subsection{Test setup}

The experiments were performed in the testing facilities of AIDICO (Instituto Tecnológico de la Construcción) in Valencia, Spain. The tests were carried out in a $5 \times 3 \mathrm{~m}$ horizontal furnace equipped with a hydraulic jack of $1000 \mathrm{kN}$ maximum capacity and a total of 16 gas burners, located at mid-height of the furnace chamber. Fig. $2 b$ presents a general view of the testing furnace.

The test setup was similar to that used in previous experimental programs performed by the authors [32][33]. The columns were placed vertically inside the furnace, fixed (F) at their bottom end and pinned (P) at their top end. The load was on a first instance applied to the columns at room temperature, and afterwards and maintaining the load constant, the gas burners were activated, following the standard ISO 834 [34] fire curve. A schematic view of the test setup can be seen in Fig. 4a.

For the eccentrically loaded columns, a special knife bearing was designed, which allowed applying the desired load eccentricity: 20 or $50 \mathrm{~mm}$. Also here, and in order to avoid any interaction between the strong and weak axis, the eccentricities were applied in all cases about the weak axis.

\subsection{Column specimens}

The length of the columns was $3180 \mathrm{~mm}$, although only $2970 \mathrm{~mm}$ were directly exposed to the fire inside the furnace, as indicated in Fig. 4a.

For each column specimen, two vent holes of $15 \mathrm{~mm}$ diameter were drilled in the steel hollow section wall at $100 \mathrm{~mm}$ from each column end. These vent holes were provided for relieving the water vapour pressure produced during the experiment. An additional hole, located near the bottom end of the columns, was used for connecting the thermocouple wires. 


\subsection{Instrumentation}

The temperature evolution at different points of the column specimens was registered during the fire tests by means of a set of type K thermocouples (TC), arranged as given in Fig. 4. Seven thermocouples (TC1 to TC7) were located at the mid-length of the column, and an additional thermocouple (TC8) was located at 3/4 times the height of the column. TC1, TC7 and TC8 were located at the steel tube exposed surface, while the other 5 thermocouples (TC2 to TC6) were embedded in the concrete core.

The temperature inside the furnace chamber was automatically registered and controlled during the tests by means of 6 plate thermocouples and a pressure sensor. The axial elongation at the top end of the columns was measured during the tests by means of a LVDT located outside the furnace.

\subsection{Material properties}

Steel tubes

The same steel tubes as those used for the room temperature tests were employed in the fire tests, $220 \times 110 \times 12 \mathrm{~mm}$. The real yield strength $\left(f_{\mathrm{y}}\right)$ of the hollow steel tubes was again obtained for each column specimen by performing the corresponding coupon test (see Table 1).

\section{Concrete}

Table 1 lists the real cylinder compressive strength of concrete $\left(f_{\mathrm{c}}\right)$ for all the specimens, where calcareous aggregates were used in the concrete mix. The concrete cylinders were tested on the same day of the column fire test.

In order to measure the concrete moisture content, cubic specimens of $150 \times 150 \times 150$ $\mathrm{mm}$ were also prepared. The moisture content was obtained according to the procedure described in ISO 12570:2000 [35]. 
Reinforcing bars

The bar-reinforced specimens followed the same arrangement described previously in section 2.3 and presented in Fig. $1 b$.

\subsection{Experimental results}

The typical failure observed in all the columns was overall buckling about their minor axis. Fig. 5 shows one of the column specimens after failure, with details of the column ends. No local buckling was observed at mid-height of the column or near the column ends.

The evolution of the axial displacement measured at the top end of the column along the fire exposure time is plotted in Fig. 6a for the unreinforced columns and in Fig. $6 \mathrm{~b}$ for the barreinforced columns. The resulting fire resistance time expressed in minutes, obtained according to EN 1363-1 [36] is listed in Table 1. The axial displacement versus time curve obtained for the six column specimens tested presents only two stages in comparison with the typical four-part curve described in [23], which is due to the high slenderness of the columns. These two stages can be clearly identified in the curves plotted in Fig. 6, the first stage of these curves corresponding to the elongation of the steel tube and the second stage corresponding to the axial shortening of the column which occurs when the steel tube starts to yield. Therefore, in these tests, the concrete infill did not play an important role in the mechanical behaviour of the specimens, which is frequent in the case of columns with high slenderness [32][33].

The influence of the load eccentricity can be seen in Fig. 6a for unreinforced columns and in Fig. $6 \mathrm{~b}$ for bar-reinforced columns. As the load level applied to all the columns was the same ( $20 \%$ of their theoretical maximum capacity at room temperature), the value of the load applied to the columns with higher eccentricity was lower, and therefore the resulting fire resistance time was higher. This effect can be seen in both figures, where as the load 
eccentricity is increased, the resulting fire resistance time also increases. Note that the load applied to the concentrically loaded columns was approximately two times the load applied to the columns with $50 \mathrm{~mm}$ eccentricity, while the difference in terms of fire resistance time was not proportional to the load increment, with a $25 \%$ time increment if specimens F-E-50/F-E00 are compared and a $15.4 \%$ for specimens F-RE-50/F-RE-00.

The addition of reinforcing bars did not produce a noticeable difference in terms of fire resistance when comparing at the same load level, although it is worth noting that the value of the load applied to the reinforced columns was slightly higher than that applied to their unreinforced counterparts. Nevertheless, it can be seen that, although the load applied to the reinforced specimens was higher, the values of their fire resistance were similar or in some cases higher than that of the unreinforced columns (see F-E-00/F-RE-00), which confirms the favourable effect of the contribution of the reinforcing bars in the fire situation.

\section{STUDY AND DISCUSSION OF EUROCODE 4}

\subsection{Room temperature design}

In this section, the simplified method of design in Clause 6.7.3 of EN 1994-1-1 [17] will be assessed against the results of the room temperature tests carried out in this experimental program. Specimens E-00 and RE-00 will be evaluated with the method in Clause 6.7.3.5 for members in axial compression, while specimens E-20, E-50, RE-20 and RE-50 will be calculated with the method in Clause 6.7.3.6, for members in combined compression and uniaxial bending. For members in axial compression, the design value of the normal force can be obtained through the corresponding buckling curves according to Clause 6.7.3.5(2), while for combined compression and uniaxial bending, the members must be verified using second order analysis. For that purpose, the interaction curve must be determined as given in 6.7.3.2. As a simplification, the interaction curve can be replaced by a polygonal diagram. 
The relevant points of the polygonal interaction curve have been calculated as indicated in the CIDECT Design Guide [37] for concrete filled hollow section columns. The expression for the plastic section modulus of the hollow steel tube $\left(W_{p a}\right)$ has been obtained from EN 10210-2 [38], equation (1), while for the concrete core $\left(W_{p c}\right)$ the corresponding expression has been derived from that of the steel tube, equation (2). $W_{p s}$ represents the plastic section modulus of the reinforcing bars. These expressions are valid for bending about the weak axis.

$$
\begin{aligned}
& W_{p a}=\frac{(2 b)^{2} \cdot(2 a)-(2 b-2 t)^{2} \cdot(2 a-2 t)}{6} \\
& W_{p c}=\frac{(2 b-2 t)^{2} \cdot(2 a-2 t)}{6}-W_{p s}
\end{aligned}
$$

The distance $h_{n}$ from the centre-line of the composite cross-section to the neutral axis in the situation of pure bending (internal axial force zero) can be evaluated through the following expression, which has been adapted from the equation for rectangular hollow sections of the CIDECT Design Guide [37], by introducing the major axis dimension $2 a$ in the denominator, considering bending about the weak axis:

$$
h_{n}=\frac{A_{c} \cdot f_{c}-A_{s n} \cdot\left(2 f_{s}-f_{c}\right)}{2 \cdot(2 a) \cdot f_{c}+4 t \cdot\left(2 f_{y}-f_{c}\right)}
$$

where $A_{s n}$ is the area of the reinforcing bars within the region of depth $h_{n}$ from the centre-line of the composite cross-section.

This expression provides an approximation, as the exact determination of $h_{n}$ for elliptical sections would result rather complicated because of the variable width in this region. It should be noted that the same approximation is also adopted in the CIDECT Design Guide for circular columns with a reasonable accuracy, with an error lower than a 3\% [37].

This assumption is also confirmed by the recently published Design Guide for Concrete Filled SHS Columns for UK [39], which includes in its Appendix A, section A.1.3 the same approximate expression for evaluating $h_{n}$ for the case of elliptical hollow sections. 
The plastic section moduli of the corresponding components within the region of $2 h_{n}$ may be evaluated as follows:

$$
\begin{aligned}
& W_{p a n}=2 t \cdot h_{n}^{2} \\
& W_{p c n}=(2 a-2 t) \cdot h_{n}^{2}-W_{p s n}
\end{aligned}
$$

The expression of $W_{p c n}$ has been also adapted from the corresponding equation for rectangular hollow sections, as it is also done for circular columns [37] [39]. $W_{p s n}$ corresponds to the plastic section modulus of the reinforcing bars included in the region of depth $2 h_{n}$.

With the use of equations (1) to (5), the interaction curve has been built up for each column specimen, and the rules in Clause 6.7.3.5 and Clause 6.7.3.6 applied for obtaining the ultimate load. The results are summarized in Table 2, where axially and eccentrically loaded columns have been separated in two groups. In this table, the errors are computed as the test value divided by the EC4 prediction. As it can be seen, the method in EC4 provides safe results on average for both concentrically and eccentrically loaded columns, with a lower dispersion in the case of the second group. It can be also observed that while for all the unreinforced columns safe results are obtained (errors over 1.00), in some of the barreinforced columns unsafe results are obtained (errors under 1.00), although with a good approximation to the experimental result.

It is worth reminding that the result of test E-00 is not reliable, due to the anomalous behaviour previously described, and its ultimate load should be closer to that of test RE-00, which would give a lower error.

With all the exposed above, it can be concluded that the methods in EC4 for members in axial compression or in combined compression and uniaxial bending (weak axis) provide reasonably accurate results for evaluating the buckling resistance of concrete filled elliptical hollow section columns. Further tests would be needed for evaluating the accuracy of EC4 method when eccentricity is applied about the strong axis. 


\subsection{Fire resistance evaluation}

\subsubsection{EN 1994-1-2 Clause 4.3.5.1}

In this section, the test results will be employed to study and discuss the current provisions of EN 1994-1-2 [24]. Clause 4.3.5.1 of this standard presents a general simple calculation model for composite columns, which provides a method for calculating the design value of the buckling resistance of columns subjected to concentric axial loads in the fire situation. Although elliptical sections are not included in EC4, the application of the method to CFEHS columns will be assessed in this section.

As part of the method, the effective flexural stiffness of the columns needs to be calculated, being defined in Clause 4.3.5.1(5) as:

$$
(E I)_{f i, e f f}=\sum_{j}\left(\varphi_{a, \theta} E_{a, \theta} I_{a, \theta}\right)+\sum_{k}\left(\varphi_{s, \theta} E_{s, \theta} I_{s, \theta}\right)+\sum_{m}\left(\varphi_{c, \theta} E_{c, s e c, \theta} I_{c, \theta}\right)
$$

The evaluation of this equation requires the definition of a set of reduction coefficients $\left(\varphi_{i, \theta}\right)$ to account for the effect of the thermal stresses. Nevertheless, the values of these coefficients are not specified in the code for CFT columns. In the absence of these values, different assumptions have been suggested in the design guidance, as to take them as equal to unity or to use the values in Annex G for partially encased steel sections [40][41].

As the method is valid for concentric axial loads, the buckling resistance of the eccentrically loaded columns analyzed in this paper will be obtained as given in Section H.4 of Annex $\mathrm{H}$ in EC4. On a first instance, the design value of the resistance under concentric axial load will be calculated and, afterwards, the resulting buckling load will be corrected by means of two coefficients given in Figures H.1 and H.2 of Annex H, in order to obtain the corresponding buckling resistance of the columns under eccentric loads. The first coefficient, $\varphi_{s}$, is a function of the percentage of reinforcement, and the second coefficient, $\varphi_{\delta}$, is a function of the eccentricity and the slenderness of the column. 
For all the columns, the test results are compared with the predictions from EC4 simple calculation model, in terms of the axial buckling load at the time of failure. For that purpose, the cross-sectional temperature field at the time of test failure is previously obtained for all the columns using the measured temperatures, and afterwards the buckling resistance is obtained as given in Clause 4.3.5.1 of EC4, with the correction described above for taking into account the load eccentricity.

For obtaining the temperature distribution, the column cross-section was subdivided into a number of concentric elliptical layers of the same thickness, in particular one layer for the steel tube and six layers for the concrete core. The criterion employed by the authors for subdividing the cross-section was that the resulting layers had a thickness lower than $20 \mathrm{~mm}$, in order to be representative enough. The temperatures at the different layers were obtained by using linear interpolation from the measured temperatures at the locations of the thermocouples.

Once the temperature distribution at the time of failure was obtained, the buckling resistance of all the tested columns was calculated by means of the described method. The results are summarized in Table 3 , where the analyzed cases have been divided into two categories: concentrically loaded columns and eccentrically loaded columns. In this table, the errors are computed as the test value divided by the EC4 prediction. A comparison between the calculated buckling loads and the test loads can be seen graphically in Fig. 7.

As it can be seen, the simple calculation model in EC4 produced unsafe results for concentrically loaded columns, with an average value of the error equal to 0.85 and a standard deviation of 0.05 . It is worth noting that the columns tested had a high slenderness value in all cases. This result confirms that the code produces unsafe results for concentrically loaded slender columns when the effect of the thermal stresses is neglected (i.e. flexural stiffness 
reduction coefficients equal to unity), as was obtained by the authors in previous investigations for circular columns [26] [32].

In turn, for eccentrically loaded columns, the method produced safe results, the mean error value being 1.71 and the standard deviation 0.18 . Nevertheless, despite the simple calculation model provides safe predictions in these cases, it results excessively conservative, with high prediction errors (over 1.5). This is due to the low values of the coefficients $\varphi_{s}$ and $\varphi_{\delta}$ obtained from Annex H (see Table 3), which penalize highly the values of the calculated buckling loads. In fact, the correction coefficients from Annex $\mathrm{H}$ for eccentrically loaded columns are not prepared to be used in combination with the simple calculation model in Clause 4.3.5.1, but have been applied here in the lack of specific guidance for accounting for the load eccentricity in Clause 4.3.5.1. Therefore, it is suggested that specific correction coefficients are derived for eccentric loads to be used in combination of the simple calculation model for CFT columns with elliptical section and other section shapes.

\subsubsection{Design proposal}

A design proposal for evaluating the fire resistance of CFEHS columns subjected to concentric axial load was developed by the authors of this paper [27], based on the results of parametric studies.

In the first part of the proposal, specific equations for evaluating the cross-sectional temperature field of elliptical CFT columns were given. A single equivalent temperature for the whole concrete core and another one for the steel tube were proposed, so as to obtain the same fire resistance of the column as by using the real non-uniform temperature distribution. For the case of bar-reinforced columns, an additional equation for evaluating the temperature of the reinforcing bars was proposed. These expressions include the effect of the section factor $\left(A_{m} / V\right)$ and the fire resistance period $(R)$.

Equivalent temperature of the concrete core: 


$$
\theta_{c, e q}=-395.503+9.304 R-0.035 R^{2}+33.698 A_{m} / V-0.425\left(A_{m} / V\right)^{2}+0.035 R \cdot A_{m} / V
$$

Equivalent temperature of the steel tube:

$$
\theta_{a, e q}=300.845+11.209 R-0.044 R^{2}+4.219 A_{m} / V-0.029 R \cdot A_{m} / V
$$

Equivalent temperature of the reinforcing bars:

$$
\theta_{s, e q}=-255.1+10.106 R-0.039 R^{2}+8.036 A_{m} / V+0.062 R \cdot A_{m} / V
$$

In the second part of the design proposal, a specific formulation was developed for obtaining the values of the flexural stiffness reduction coefficients $\left(\varphi_{i, \theta}\right)$ to use in equation (1) in the case of CFEHS columns. For the concrete core, a constant value equal to $\varphi_{c, \theta}=0.8$ was proposed, used in combination with the initial tangent stiffness. Note that EC4 defines the concrete stiffness in fire design using the secant modulus for the peak of the stress-strain curve. The tangent modulus in origin is 1.5 times the secant modulus, therefore $\varphi_{c, \theta}=0.8 \times 1.5$ $=1.2$ if the secant modulus is used.

For the steel tube, a specific equation for evaluating the reduction coefficient was obtained by means of a multiple nonlinear regression analysis:

$$
\varphi_{a, \theta}=\varphi_{a, \theta 1}\left(D_{e q} / t\right) \times\left(1.73-0.72 \cdot\left(A_{m} / V\right)^{0.047}\right) \times\left(0.118+0.0015 \cdot\left(\ell_{\theta} / 2 b\right)^{1.72}\right) \leq 1
$$

In this equation, the reduction coefficient $\varphi_{a, \theta}$ is a product of two partial reduction coefficients lower than unity, $\varphi_{a, \theta 2}$ and $\varphi_{a, \theta 3}$, which must be corrected by the factor $\varphi_{a, \theta 1}$ as a function of $D_{e q} / t$ only for stocky columns $\left(\ell_{\theta} / 2 b \leq 12\right)$, using the values given in Espinos et al. [27]. For $\ell_{\theta} / 2 b>12$, the factor $\varphi_{a, \theta l}$ is equal to unity. The equivalent diameter for evaluating the first term in this equation is defined as $D_{e q}=P / \pi$, being $P$ the perimeter of the elliptical section. 
For bar-reinforced columns, the reduction coefficient of the reinforcing bars $\left(\varphi_{s, \theta}\right)$ and the corresponding buckling curve can be obtained from Espinos et al. [27], as a function of the percentage of reinforcement.

The design proposal for elliptical columns is next verified against the results of the fire tests presented in this paper. On a first approach, the temperature field obtained from the experiments is used, where the representative temperatures of the different layers in which the cross-section is subdivided are interpolated from the measurements at the location of the thermocouples.

On a second approach, the equivalent temperatures of the steel tube, concrete core and reinforcing bars are evaluated through equations (7) to (9), with only one temperature used for representing each component of the cross-section.

After obtaining the corresponding temperatures for the steel tube, concrete core and reinforcing bars, the proposed simple calculation method described in Espinos et al. [27] is applied for evaluating the design axial buckling load of the columns in the fire situation, using equation (10) for calculating the flexural stiffness reduction coefficient of the steel tube $\left(\varphi_{a, \theta}\right)$. For the case of the bar-reinforced specimens, given the value of the percentage of reinforcement $(2.37 \%)$, a reduction coefficient $\varphi_{s, \theta}=0.6$ has been applied to the reinforcing bars and buckling curve "b" has been selected, according to Espinos et al. [27].

It is worth noting that the proposed method given in Espinos et al. [27] is only valid for concentrically loaded columns. In the absence of a method for evaluating the fire resistance of eccentrically loaded CFEHS columns, the coefficients given in Section H.4 of EC4 Annex H will be used for correcting the calculated buckling loads obtained for these columns with the proposed method for concentric loads. 
Table 4 summarises the results obtained under the two approaches (equivalent temperatures and measured temperatures), for both concentrically and eccentrically loaded columns.

A comparison between the predicted buckling loads and the test loads can be seen graphically in Fig. 7, for the case of using the equivalent temperatures, where these results have been superimposed with those obtained previously with EC4 method.

As it can be seen, the proposed method produced safe results for concentrically loaded columns, solving the unsafety of the current method in EC4. A lower error was obtained when using the equivalent temperatures calculated with the proposed equations (1.33 average error versus 1.59 with the measured temperatures).

Regarding the eccentrically loaded columns, the method produced safe results as well, although with high errors (2.53 average error with the equivalent temperatures and 3.19 with the measured temperatures), resulting excessively conservative. This is due again to the low values of the coefficients $\varphi_{s}$ and $\varphi_{\delta}$ from Figures H.1 and H.2 of Annex H, which penalize highly the values of the calculated buckling loads. Note that the use of the correction coefficients from Annex $\mathrm{H}$ for eccentrically loaded columns in combination with the simple calculation model in Clause 4.3.5.1 has been done as a tentative approach in this paper, however it has been proved not to be a good practice, resulting in over-conservative predictions.

Therefore, specific correction coefficients to take into account the load eccentricity and percentage of reinforcement should be developed, in order to extend the validity of the proposed method to eccentrically loaded CFEHS columns, as it was also observed by the authors for circular columns [33]. 


\section{SUMMARY AND CONCLUSIONS}

The results of an experimental program on slender elliptical hollow section columns filled with concrete under room and elevated temperatures have been presented in this paper. Given the reduced number of experiments found in the literature, this work provides novel results to the research community. The test parameters covered in this experimental program were the load eccentricity and the type of concrete infill. Six tests were performed at room temperature, while other six fire tests were also carried out.

From the test results at room temperature, it was found that the reinforcing bars do not improve the load-bearing capacity of the columns when eccentricity is applied about the weak axis. For concentrically loaded columns, it was observed that small differences in the initial eccentricity due to bow imperfections can have a significant effect in the buckling resistance of the columns. In the fire situation, the addition of reinforcing bars had a favorable effect on the response of the columns, although only small increments in terms of fire resistance time were occasionally obtained.

Using the tests results, the design rules in Eurocode 4 have been assessed, and the proposal by the authors has been also evaluated. Through the results of this study, it has been confirmed that the methods in EC4 Part 1.1 for members in axial compression or in combined compression and uniaxial bending (weak axis) provide accurate results for evaluating the buckling resistance of CFEHS columns, although further tests are needed for evaluating the method for bending about the strong axis.

In turn, the simple calculation model in Part 1.2 of EC4 did not produce such level of accuracy. When comparing against the fire tests carried out on this research, unsafe results were obtained for concentrically loaded columns using flexural stiffness reduction coefficients equal to unity, which confirms the results obtained by the authors in previous investigations for slender circular columns. Nevertheless, for eccentrically loaded columns, 
the method produced safe predictions, although with high errors due to conservativeness of the reduction coefficients from Annex $\mathrm{H}$.

Regarding the method proposed by the authors, it produced safe results for both concentrically and eccentrically loaded columns, although resulting excessively conservative for the second group, as the reduction coefficients from Annex $\mathrm{H}$ were used. Therefore, it is concluded that specific correction coefficients should be developed, in order to extend the validity of the proposed method to eccentrically loaded CFEHS columns.

\section{ACKNOWLEDGEMENTS}

The authors would like to express their sincere gratitude to the European Union for the help provided through the Project RFSR-CT-2012-00025, carried out with a financial grant of the Research Programme of the Research Fund for Coal and Steel.

\section{REFERENCES}

[1] Gardner L, Chan TM. Cross-section classification of elliptical hollow sections. Steel and Composite Structures 2007; 7(3):185-200.

[2] Gardner L, Chan TM, Wadee MA. Shear response of elliptical hollow sections. Structures and Buildings 2008; 161(6):301-309.

[3] Chan TM, Gardner L. Compressive resistance of hot-rolled elliptical hollow sections. Engineering Structures 2008; 30(2):522-532.

[4] Chan TM, Gardner L. Bending strength of hot-rolled elliptical hollow sections. Journal of Constructional Steel Research 2008; 64(9):971-986.

[5] Chan TM, Gardner L. Flexural buckling of elliptical hollow section columns. Journal of Structural Engineering (ASCE) 2009; 135:546-557.

[6] Ruiz-Teran AM, Gardner L. Elastic buckling of elliptical tubes. Thin-Walled Structures 2008; 46(11):1304-1318. 
[7] Silvestre N. Buckling behaviour of elliptical cylindrical shells and tubes under compression. International Journal of Solids and Structures 2008; 45(16):4427-4447.

[8] Chan TM, Gardner L, Law KH. Structural design of elliptical hollow sections: a review. Structures and Buildings 2010; 163(6):391-402.

[9] Gardner L, Chan TM, Abela JM. Structural behaviour of elliptical hollow sections under combined compression and uniaxial bending. Advanced Steel Construction 2011; 7(1):86-112.

[10] Law KH, Gardner L. Lateral instability of elliptical hollow section beams. Engineering Structures 2012; 37:152-166.

[11] Yang H, Lam D, Gardner L. Testing and analysis of concrete-filled elliptical hollow sections. Engineering Structures 2008; 30:3771-3781.

[12] Zhao XL, Packer JA. Tests and design of concrete-filled elliptical hollow section stub columns. Thin-Walled Structures 2009; 47:617-628.

[13] Lam D, Gardner L, Burdett M. Behaviour of axially loaded concrete filled stainless steel elliptical stub columns. Advances in Structural Engineering 2010; 13(3):493-500.

[14] Dai X, Lam D. Numerical modelling of the axial compressive behaviour of short concrete-filled elliptical steel columns. Journal of Constructional Steel Research 2010; 66:931-942.

[15] Sheehan T, Dai XH, Chan TM, Lam D. Structural response of concrete-filled elliptical steel hollow sections under eccentric compression. Engineering Structures 2012; 45: 31423.

[16] Jamaluddin N, Lam D, Dai XH, Ye J. An experimental study on elliptical concrete filled columns under axial compression. Journal of Constructional Steel Research 2013; 87:616. 
[17] CEN. EN 1994-1-1, Eurocode 4: Design of composite steel and concrete structures. Part 1-1: General rules and rules for buildings. Brussels, Belgium: Comité Européen de Normalisation; 2004.

[18] Scullion T, Ali F, Nadjai A. Experimental study on performance of elliptical section steel columns, under hydrocarbon fire. Journal of Constructional Steel Research 2011; 67(6):986-991.

[19] Scullion T, Ali F, Nadjai A. Effect of axial restraint on the performance of elliptical hollow section steel columns, in hydrocarbon fire. Engineering Structures 2011; 33(12):3155-3161.

[20] Scullion T, Ali F, Nadjai A. Finite element numerical evaluation of elliptical hollow section steel columns in fire. Thin-Walled Structures 2012; 55:22-36.

[21] Espinos A, Gardner L, Romero M, Hospitaler A. Fire behaviour of concrete filled elliptical steel columns. Thin-Walled Structures 2011; 49(2):239-255.

[22] Dai XH, Lam D. Shape effect on the behaviour of axially loaded concrete filled steel tubular stub columns at elevated temperature. Journal of Constructional Steel Research $2012 ; 73: 117-127$.

[23] Espinos A, Romero ML, Hospitaler A. Advanced model for predicting the fire response of concrete filled tubular columns. Journal of Constructional Steel Research 2010; 66:1030-1046.

[24] CEN. EN 1994-1-2, Eurocode 4: Design of composite steel and concrete structures. Part 1-2: General rules - Structural fire design. Brussels, Belgium: Comité Européen de Normalisation; 2005. 
[25] AFNOR. Calcul simplifié de la résistance au feu des profils creux remplis de béton exposés aux conditions d'incendie normalisé. Annexe PCRB, pp. 9-16, NF-EN 1994-12/NA. Paris, France: Association Française de Normalisation; 2007.

[26] Espinos A, Romero ML, Hospitaler A. Simple calculation model for evaluating the fire resistance of unreinforced concrete filled tubular columns. Engineering Structures 2012; 42:231-244.

[27] Espinos A, Romero ML, Hospitaler A. Fire design method for bar-reinforced circular and elliptical concrete filled tubular columns. Engineering Structures 2013; 56:384-395.

[28] Portoles JM, Serra E, Romero ML. Influence of ultra-high strength infill in slender concrete-filled steel tubular columns. Journal of constructional steel research 2013; $86: 107-114$.

[29] Portoles JM, Romero ML, Bonet JL, Filippou FC. Experimental study of high strength concrete-filled circular tubular columns under eccentric loading. Journal of constructional steel research 2011; 67(4):623-633.

[30] Hernández-Figueirido D, Romero ML, Bonet JL, Montalvá JM. Ultimate capacity of rectangular concrete-filled steel tubular columns under unequal load eccentricities, Journal of Constructional Steel Research 2012; 68:107-117.

[31] Hernández-Figueirido D, Romero ML, Bonet, JL, Montalvá JM. Influence of Slenderness on High-Strength Rectangular Concrete-Filled Tubular Columns with Axial Load and Nonconstant Bending Moment, J. Struct. Eng. 2012; 138(12): 1436-1445.

[32] Romero ML, Moliner V, Espinos A, Ibañez C, Hospitaler A. Fire behavior of axially loaded slender high strength concrete-filled tubular columns. Journal of Constructional Steel Research 2011; 67(12):1953-1965. 
[33] Moliner V, Espinos A, Romero ML, Hospitaler A. Fire behavior of eccentrically loaded slender high strength concrete-filled tubular columns. Journal of Constructional Steel Research 2013; 83:137-146.

[34] ISO 834: Fire resistance tests, elements of building construction. Switzerland: International Standards Organisation; 1980.

[35] ISO 12570:2000. Hygrothermal performance of building materials and products Determination of moisture content by drying at elevated temperature.

[36] CEN. EN 1363-1, Fire resistance tests. Part 1: General requirements. Brussels, Belgium: Comité Européen de Normalisation; 1999.

[37] Bergmann R, Matsui C, Meinsma C, Dutta D. Design guide for concrete filled hollow section columns under static and seismic loading. Köln, Germany: Comité International pour le Développement et l'Etude de la Construction Tubulaire (CIDECT); 1995.

[38] CEN. EN 10210-2. Hot finished structural hollow sections of non-alloy and fine grain steels. Part 2: Tolerances, dimensions and sectional properties. Brussels, Belgium: Comité Européen de Normalisation; 2006.

[39] Wang YC. Design guide for concrete filled hot finished structural hollow section (SHS) columns. TATA Steel; 2014.

[40] Lennon T, Moore DB, Wang YC, Bailey CG. Designers' guide to EN 1991-1-2, EN 1992-1-2, EN 1993-1-2 and EN 1994-1-2. Thomas Telford Limited; 2007.

[41] Leskela MV. Inconsistencies in the fire design rules of composite columns to EN 1994-12. Steel Concrete Composite and Hybrid Structures, pp. 489-494. Leeds, England; 2009. 
Espinos A, Romero ML, Portoles JM, Hospitaler A. Ambient and fire behavior of eccentrically loaded elliptical slender concrete-filled tubular columns. J Constr Steel Res. 2014;100:97-107. doi: 10.1016/j.jcsr.2014.04.025

a)

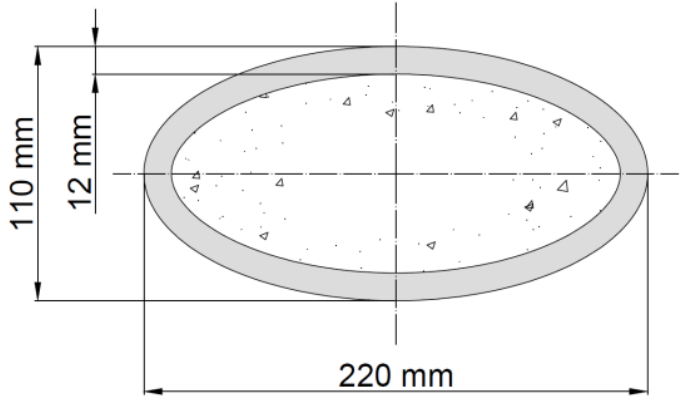

b)

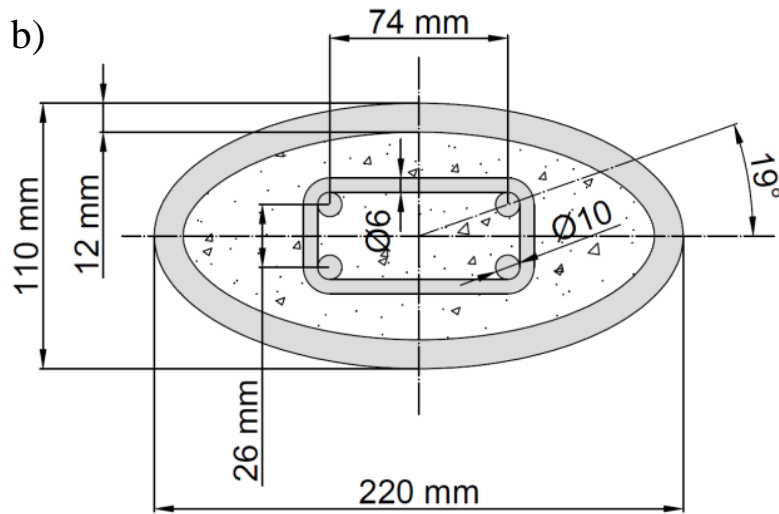

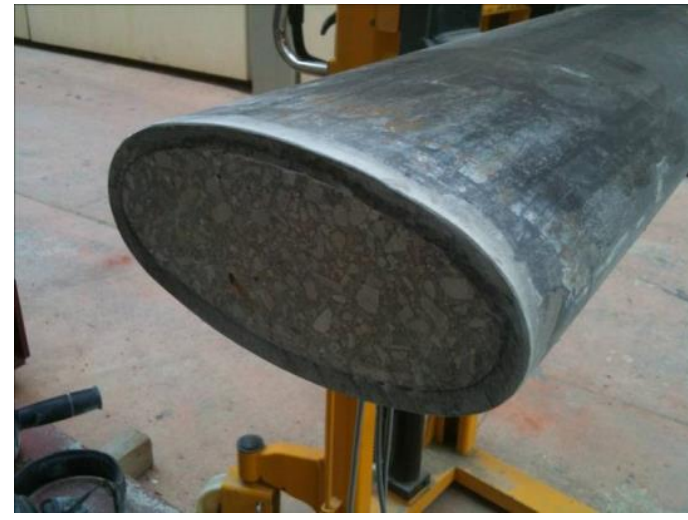

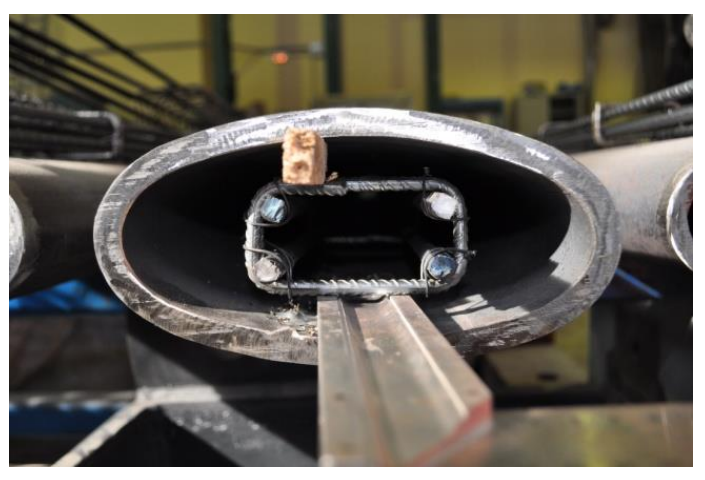

Fig. 1. Cross-sectional dimensions: a) unreinforced columns; b) reinforced columns 
a)

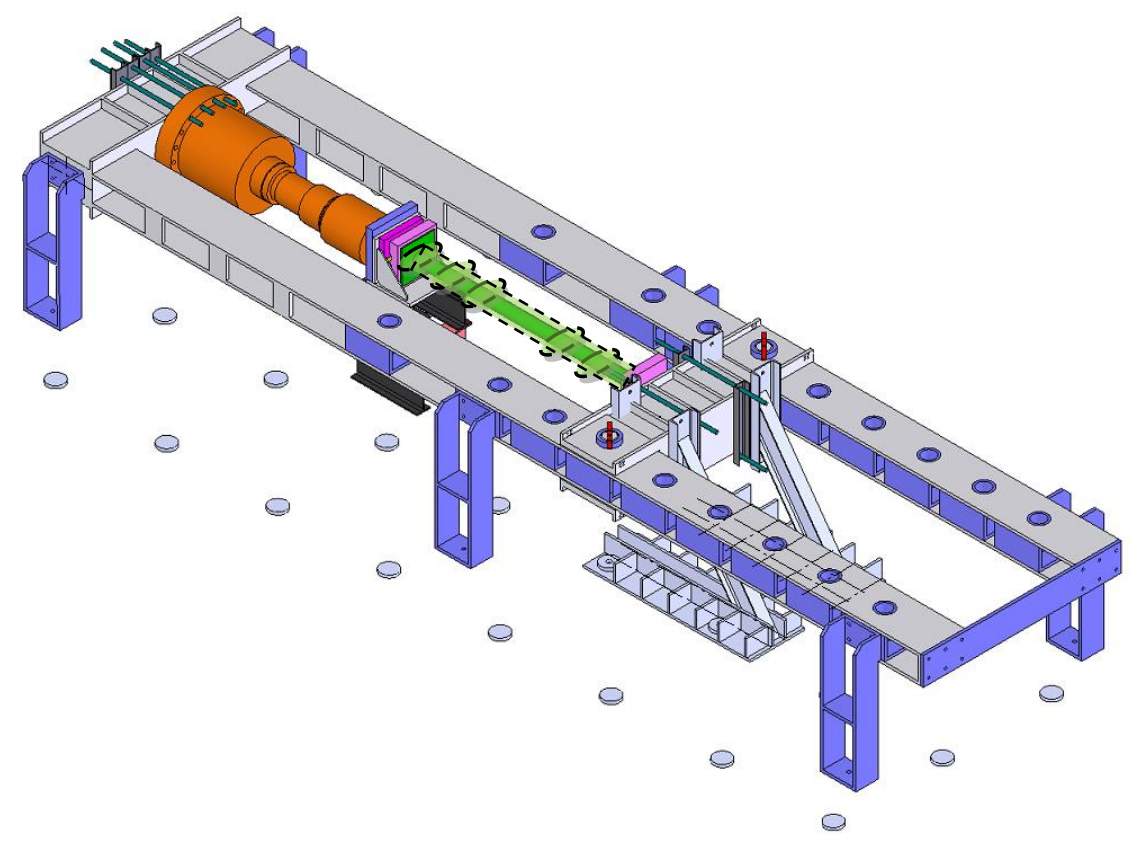

b)

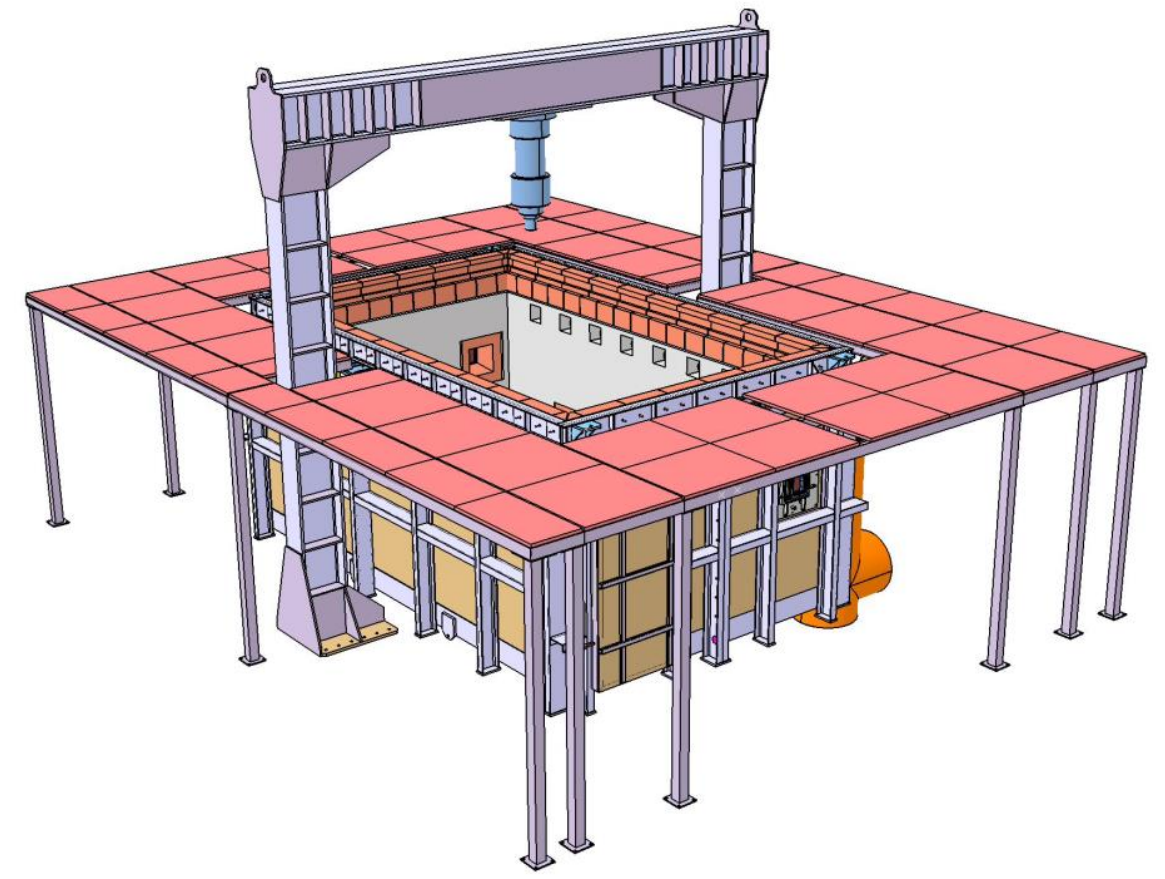

Fig. 2. Three-dimensional view of the test setup: a) room temperature test; b) fire test 


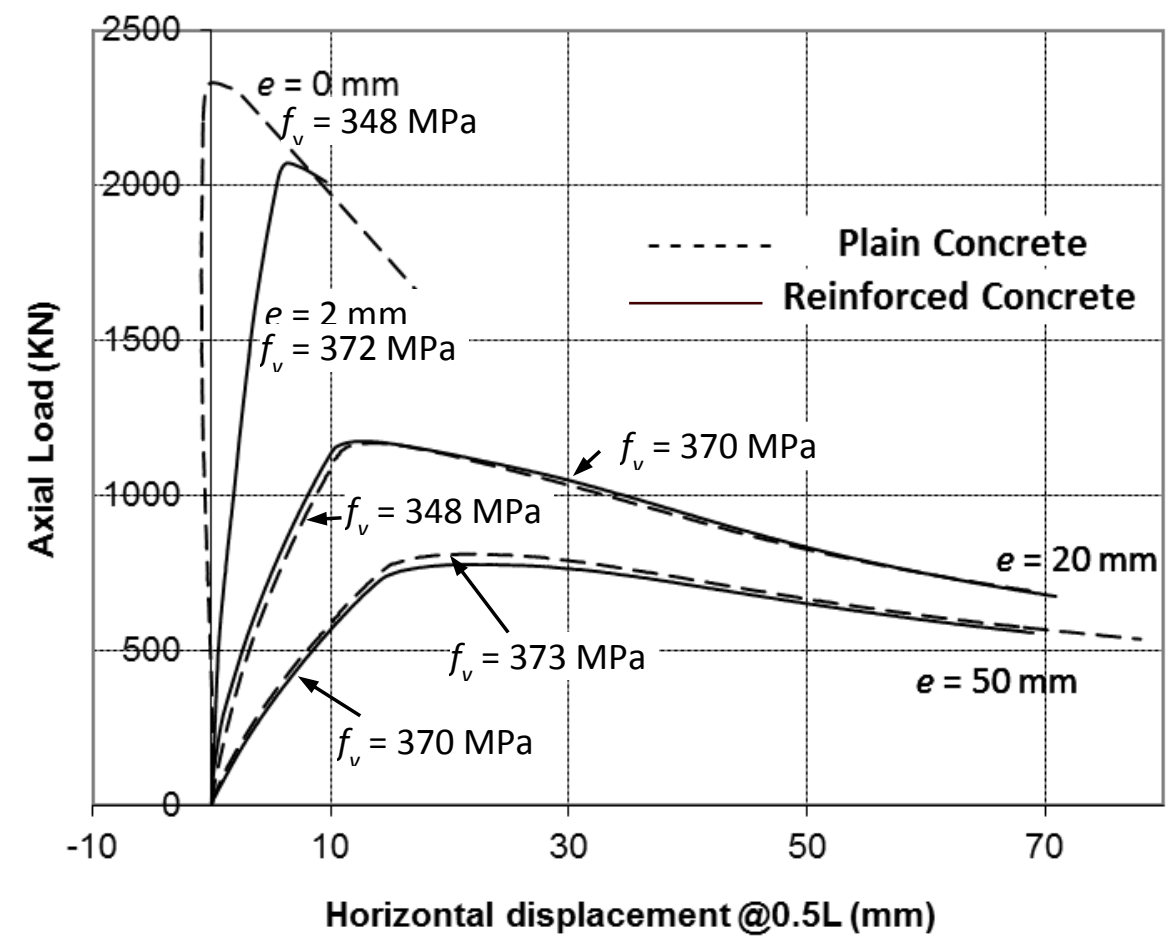

Fig. 3. Effect of the load eccentricity for room temperature tests 
a)
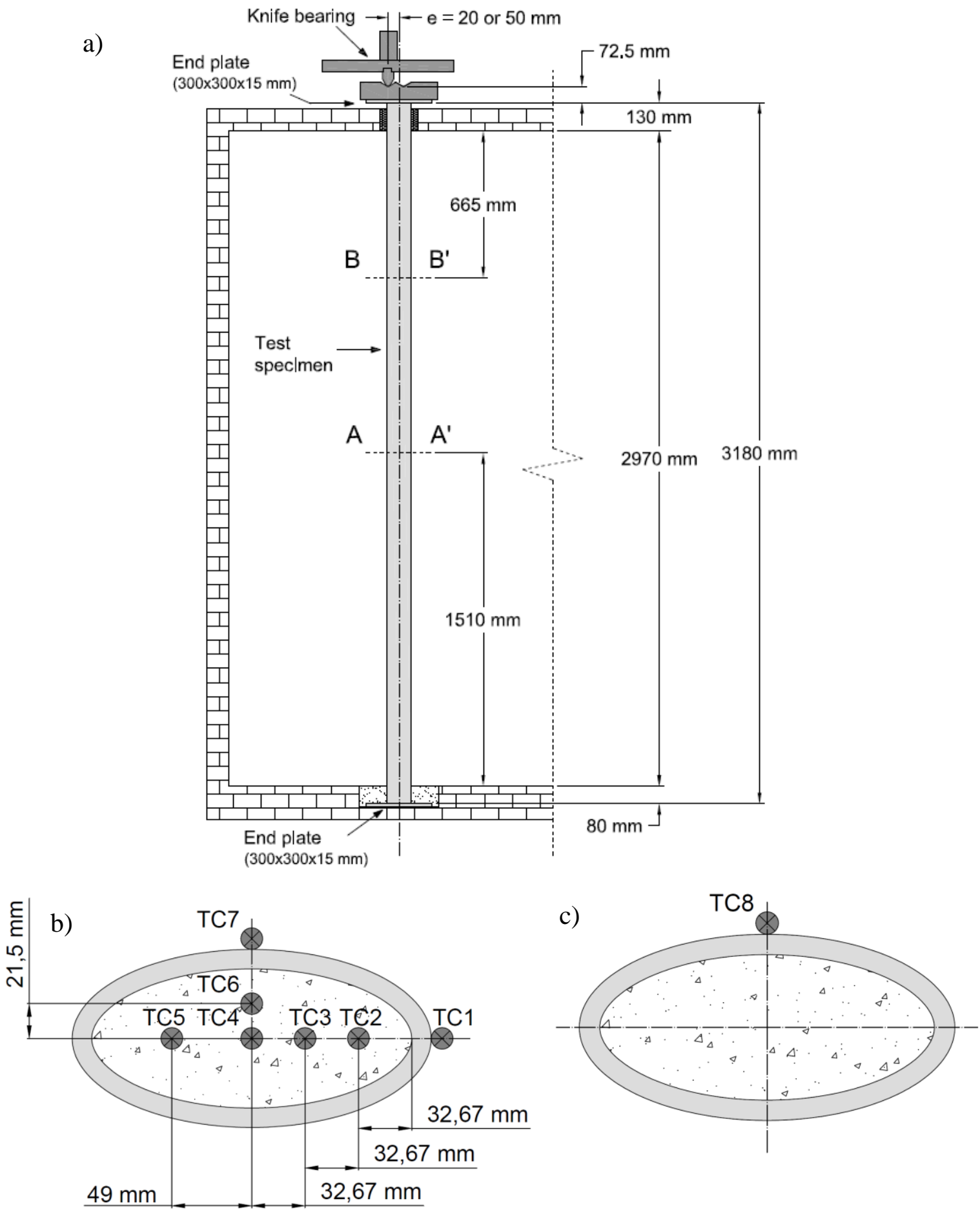

Fig. 4. a) Schematic view of the column inside the furnace; b) thermocouple location at section A-A'; c) thermocouple location at section B-B' 
Espinos A, Romero ML, Portoles JM, Hospitaler A. Ambient and fire behavior of eccentrically loaded elliptical slender concrete-filled tubular columns. J Constr Steel Res. 2014;100:97-107. doi: 10.1016/j.jcsr.2014.04.025
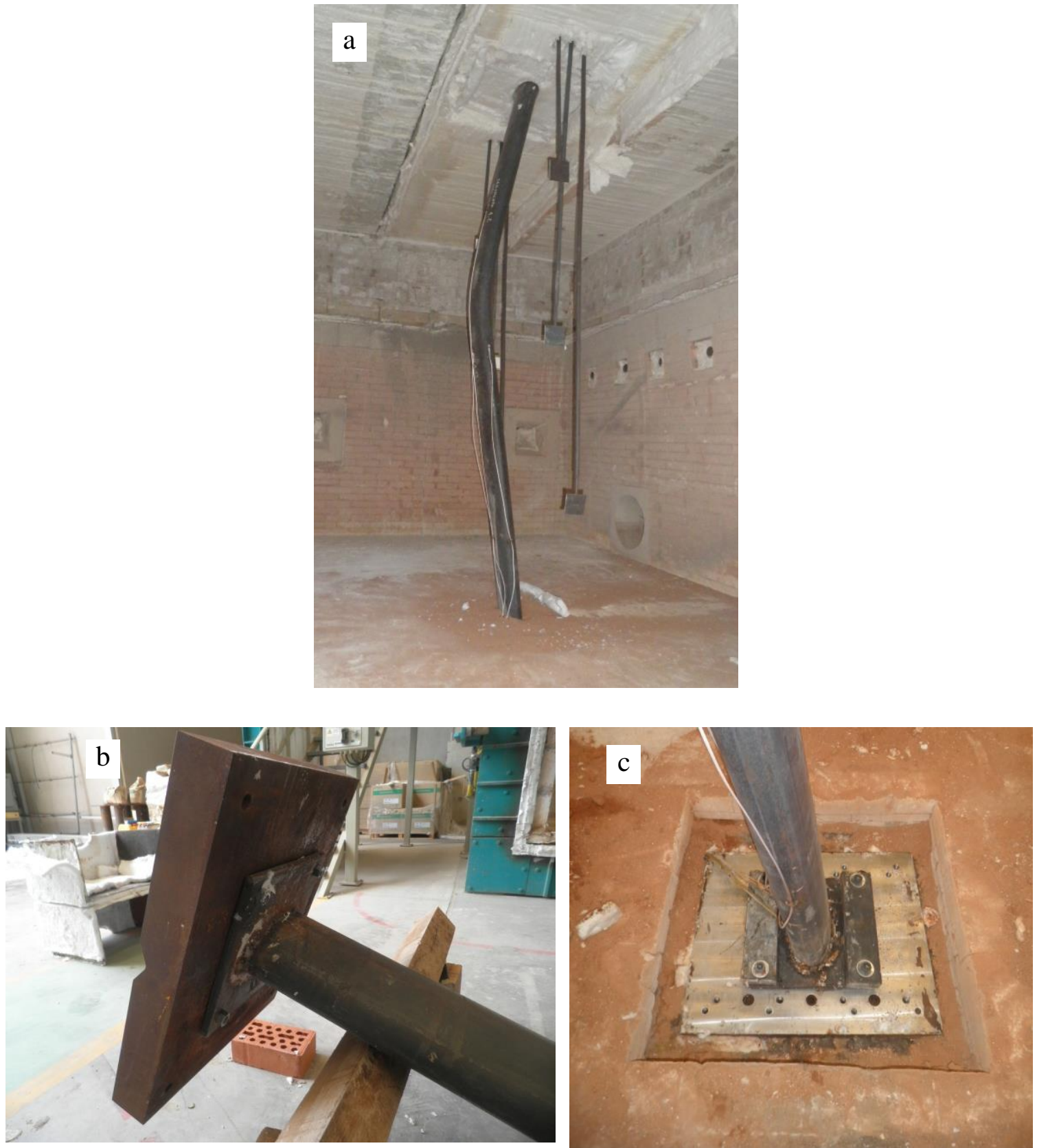

Fig. 5. Column after failure: a) general view; b) detail of the top end; c) detail of the bottom end 
a)

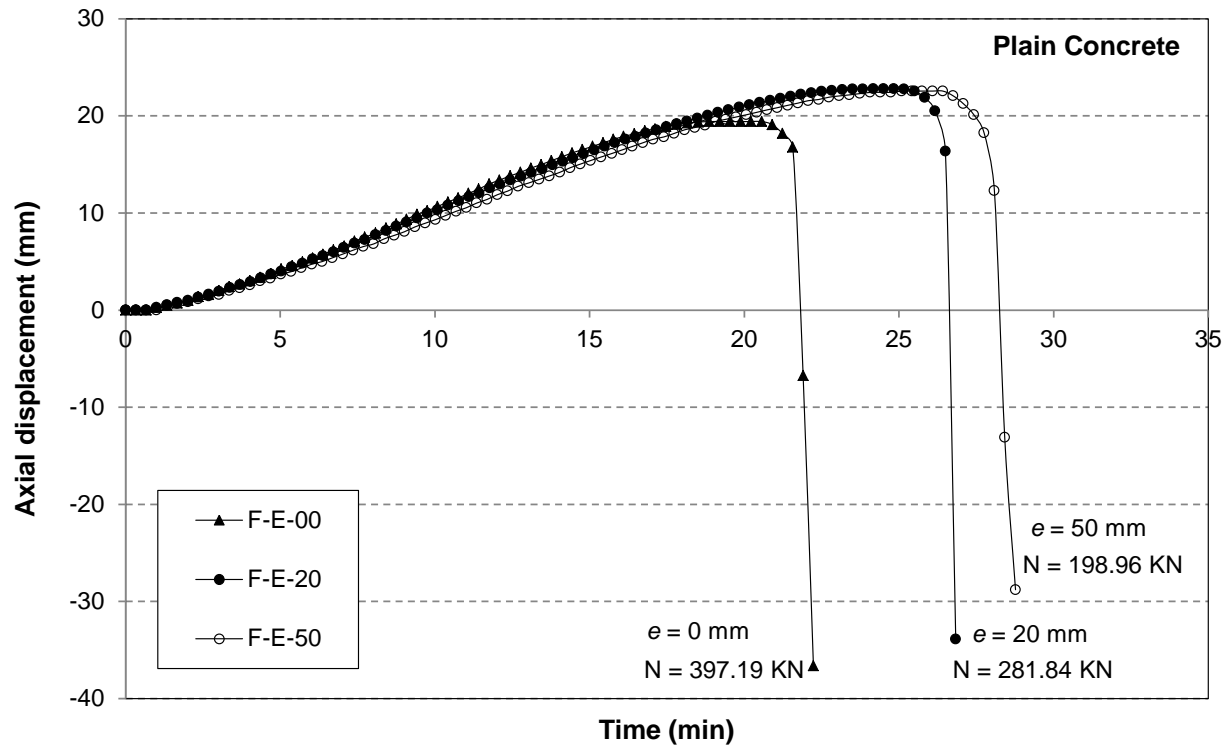

b)

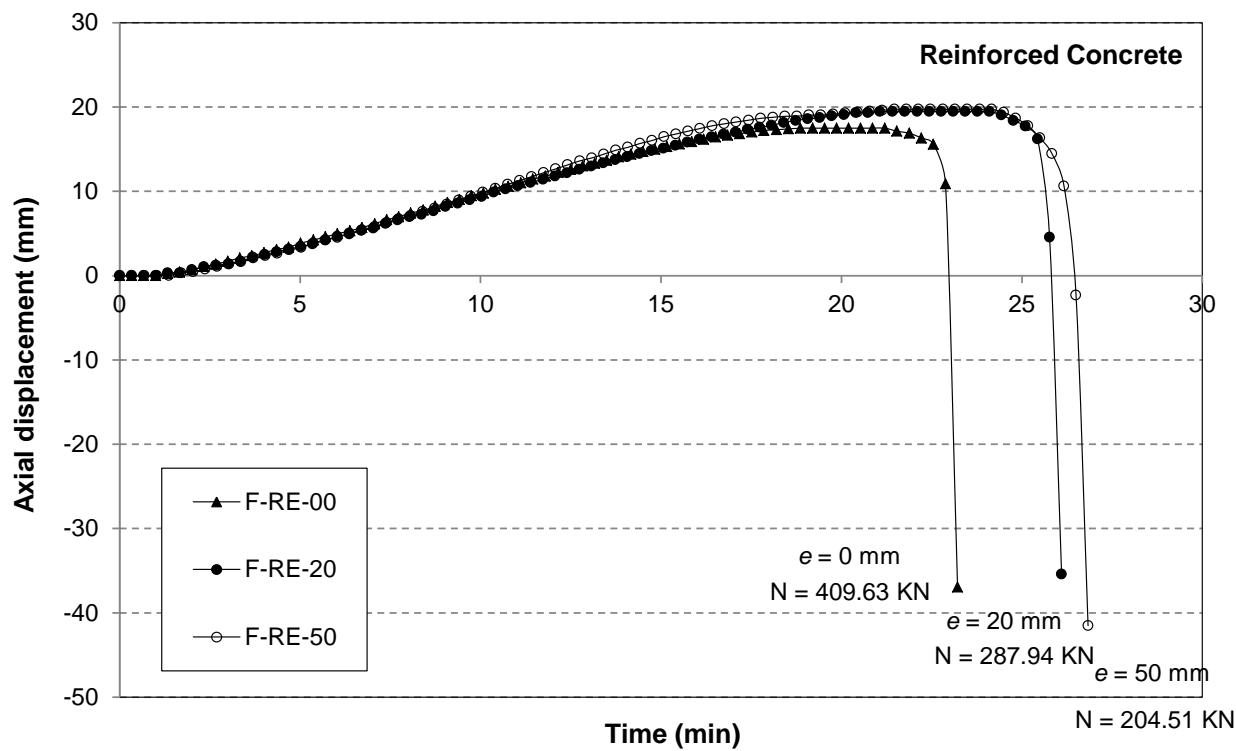

Fig. 6. Effect of the load eccentricity on the fire tests: a) unreinforced columns; b) reinforced columns 


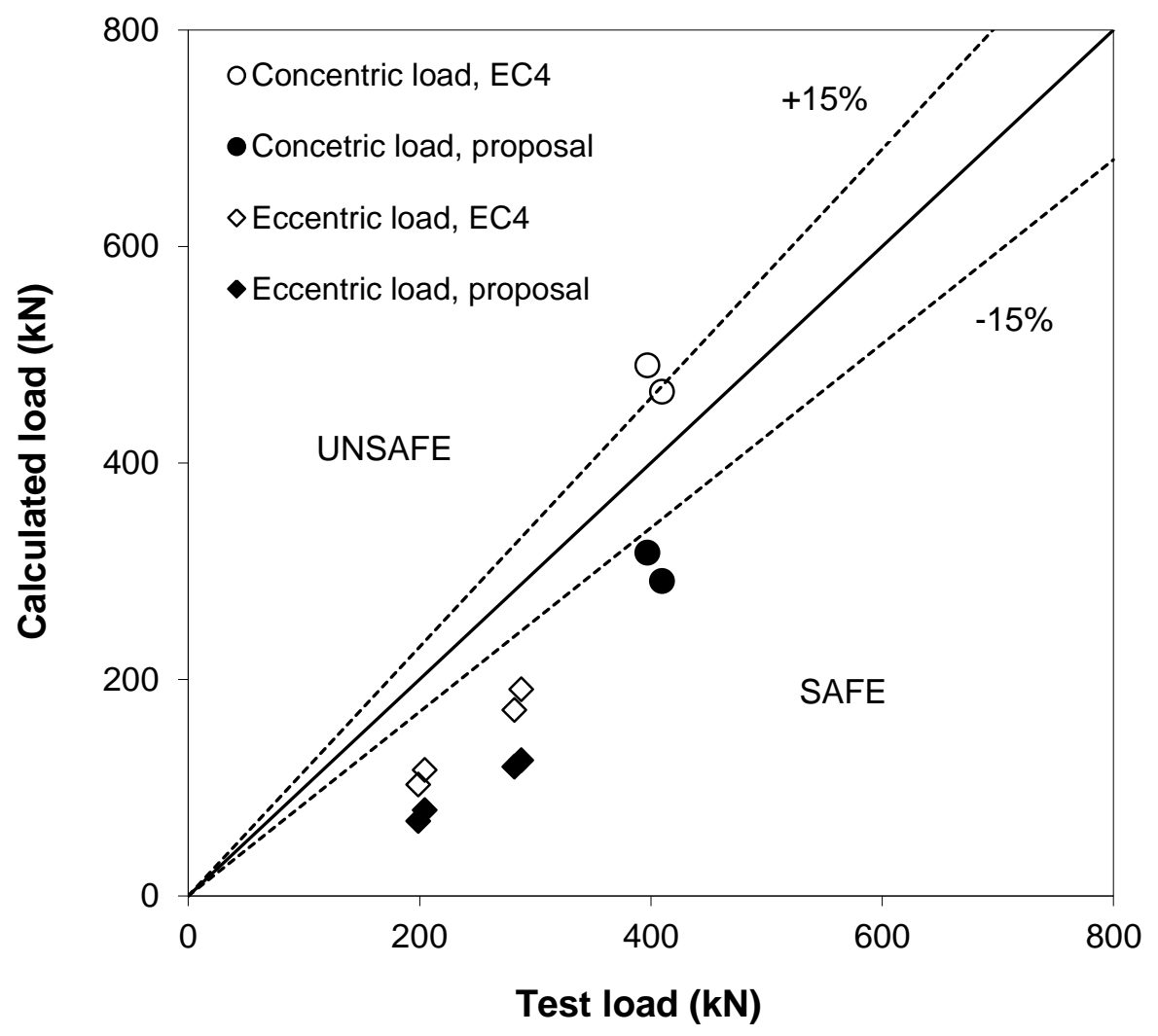

Fig. 7. Comparison between calculated buckling load and test load, with EC4 method and proposed method 
Table 1. Characteristics of the column specimens

Room temperature

\begin{tabular}{ccccccccccc}
\hline Column No. & $\begin{array}{c}\boldsymbol{L} \\
(\mathbf{m})\end{array}$ & $\boldsymbol{B} . \boldsymbol{C}$. & $\begin{array}{c}\boldsymbol{f}_{\mathbf{y}} \\
(\mathbf{M P a})\end{array}$ & $\begin{array}{c}\boldsymbol{f}_{\mathbf{c}} \\
(\mathbf{M P a})\end{array}$ & Reinf. & $\begin{array}{c}\boldsymbol{f}_{\mathbf{s}} \\
(\mathbf{M P a})\end{array}$ & $\bar{\lambda}_{y}$ & $\bar{\lambda}_{z}$ & $\begin{array}{c}\boldsymbol{e} \\
(\mathbf{m m})\end{array}$ & $\begin{array}{c}\boldsymbol{N}_{\boldsymbol{u}} \\
(\mathbf{k N})\end{array}$ \\
\hline $\mathrm{E}-50$ & 2135 & P-P & 372.45 & 37.59 & - & - & 0.45 & 0.81 & 50 & 810.37 \\
$\mathrm{E}-20$ & 2135 & P-P & 347.54 & 38.16 & - & - & 0.44 & 0.79 & 20 & 1167.95 \\
$\mathrm{E}-00^{*}$ & 2135 & $\mathrm{P}-\mathrm{P}$ & 348.06 & 37.06 & - & - & 0.44 & 0.79 & 00 & 2330.79 \\
$\mathrm{RE}-50$ & 2135 & $\mathrm{P}-\mathrm{P}$ & 369.71 & 39.38 & $4 \phi 10$ & 519 & 0.46 & 0.83 & 50 & 776.63 \\
$\mathrm{RE}-20$ & 2135 & P-P & 369.71 & 39.17 & $4 \phi 10$ & 519 & 0.46 & 0.83 & 20 & 1173.45 \\
$\mathrm{RE}-00$ & 2135 & P-P & 372.45 & 39.45 & $4 \phi 10$ & 519 & 0.46 & 0.84 & 00 & 2071.38 \\
\hline
\end{tabular}

Fire

\begin{tabular}{ccccccccccccc}
\hline Column No. & $\begin{array}{c}\boldsymbol{L} \\
(\mathbf{m})\end{array}$ & $\boldsymbol{B} . \boldsymbol{C}$ & $\begin{array}{c}\boldsymbol{f}_{\mathbf{y}} \\
(\mathbf{M P a})\end{array}$ & $\begin{array}{c}\boldsymbol{f}_{\mathbf{c}} \\
(\mathbf{M P a})\end{array}$ & Reinf. & $\begin{array}{c}\boldsymbol{f}_{\mathbf{s}} \\
(\mathbf{M P a})\end{array}$ & $\begin{array}{c}\text { Moisture } \\
(\boldsymbol{\%})\end{array}$ & $\bar{\lambda}_{y}$ & $\bar{\lambda}_{z}$ & $\begin{array}{c}\boldsymbol{e} \\
(\mathbf{m m})\end{array}$ & $\begin{array}{c}\boldsymbol{N} \\
(\mathbf{k N})\end{array}$ & $\begin{array}{c}\boldsymbol{R} \\
(\mathbf{m i n})\end{array}$ \\
\hline F-E-50 & 3180 & P-F & 348.06 & 38.17 & - & - & 3.8 & 0.46 & 0.82 & 50 & 198.96 & 28 \\
F-E-20 & 3180 & P-F & 347.54 & 39.11 & - & - & 4.1 & 0.46 & 0.83 & 20 & 281.84 & 26 \\
F-E-00 & 3180 & P-F & 372.45 & 34.72 & - & - & 4.6 & 0.47 & 0.84 & 00 & 397.19 & 21 \\
F-RE-50 & 3180 & P-F & 369.71 & 36.63 & $4 \phi 10$ & 519 & 5.2 & 0.48 & 0.87 & 50 & 204.51 & 26 \\
F-RE-20 & 3180 & P-F & 347.54 & 37.83 & $4 \phi 10$ & 519 & 4.9 & 0.47 & 0.85 & 20 & 287.94 & 25 \\
F-RE-00 & 3180 & P-F & 348.06 & 33.34 & $4 \phi 10$ & 519 & 6.1 & 0.46 & 0.84 & 00 & 409.63 & 22 \\
\hline
\end{tabular}

Table 2. Summary of the results obtained with EC4 method (room temperature tests)

\begin{tabular}{|c|c|c|c|}
\hline \multicolumn{4}{|l|}{ Concentric load } \\
\hline & $N_{u, t e s t}(\mathbf{k N})$ & $N_{u, E C 4}(\mathrm{kN})$ & $N_{u, t e s t} / N_{u, E C 4}$ \\
\hline E-00* & 2330.79 & 2003.29 & 1.16 \\
\hline \multirow[t]{3}{*}{ RE-00 } & 2071.38 & 2192.44 & 0.94 \\
\hline & & Mean & 1.05 \\
\hline & & Std. dev. & 0.15 \\
\hline \multicolumn{4}{|l|}{ Eccentric load } \\
\hline & $N_{u, t e s t}(\mathbf{k N})$ & $N_{u, E C 4}(\mathrm{kN})$ & $N_{u, t e s t} / N_{u, E C 4}$ \\
\hline E-50 & 810.37 & 770.62 & 1.05 \\
\hline E-20 & 1167.95 & 1090.85 & 1.07 \\
\hline RE-50 & 776.63 & 790.81 & 0.98 \\
\hline \multirow[t]{3}{*}{ RE-20 } & 1173.45 & 1169.49 & 1.00 \\
\hline & & Mean & 1.03 \\
\hline & & Std. dev. & 0.06 \\
\hline
\end{tabular}

* Anomalous behaviour during test 
Table 3. Summary of the results obtained with EC4 method (fire tests)

\begin{tabular}{|c|c|c|c|c|c|c|}
\hline \multicolumn{7}{|l|}{ Concentric load } \\
\hline & $N(\mathbf{k N})$ & & & & $N_{f i, R d}(\mathbf{k N})$ & $N / N_{f i, R d}$ \\
\hline F-E-00 & 397.19 & & & & 490.14 & 0.81 \\
\hline \multirow[t]{3}{*}{ F-RE-00 } & 409.63 & & & & 465.54 & 0.88 \\
\hline & & & & & Mean & 0.85 \\
\hline & & & & & Std. dev. & 0.05 \\
\hline \multicolumn{7}{|l|}{ Eccentric load } \\
\hline & $N(\mathrm{kN})$ & $N_{f i, R d, c e n t}(\mathrm{kN})$ & $\varphi_{s}$ & $\varphi \delta$ & $N_{f i, R d}(\mathbf{k N})$ & $N / N_{f i, R d}$ \\
\hline F-E-50 & 198.96 & 302.67 & 0.87 & 0.39 & 102.70 & 1.94 \\
\hline F-E-20 & 281.84 & 340.07 & 0.87 & 0.58 & 171.60 & 1.64 \\
\hline F-RE-50 & 204.51 & 342.37 & 0.87 & 0.39 & 116.17 & 1.76 \\
\hline \multirow[t]{3}{*}{ F-RE-20 } & 287.94 & 378.30 & 0.87 & 0.58 & 190.89 & 1.51 \\
\hline & & & & & Mean & 1.71 \\
\hline & & & & & Std. dev. & 0.18 \\
\hline
\end{tabular}

Table 4. Summary of the results obtained with the proposed method (fire tests)

\begin{tabular}{|c|c|c|c|c|c|}
\hline \multicolumn{6}{|c|}{ Concentric load } \\
\hline & & \multicolumn{2}{|c|}{ Equivalent temperatures } & \multicolumn{2}{|c|}{ Measured temperatures } \\
\hline & $N(\mathbf{k N})$ & $N_{f i, R d}(\mathbf{k N})$ & $N / N_{f i, R d}$ & $N_{f i, R d}(\mathbf{k N})$ & $N / N_{f i, R d}$ \\
\hline F-E-00 & 397.19 & 316.98 & 1.25 & 271.85 & 1.46 \\
\hline \multirow[t]{3}{*}{ F-RE-00 } & 409.63 & 291.02 & 1.41 & 238.99 & 1.71 \\
\hline & & Mean & 1.33 & Mean & 1.59 \\
\hline & & Std. dev. & 0.11 & Std. dev. & 0.18 \\
\hline
\end{tabular}

\begin{tabular}{|c|c|c|c|c|c|}
\hline \multicolumn{6}{|c|}{ Eccentric load } \\
\hline & \multirow[b]{2}{*}{$N(\mathbf{k N})$} & \multicolumn{2}{|c|}{ Equivalent temperatures } & \multicolumn{2}{|c|}{ Measured temperatures } \\
\hline & & $N_{f i, R d}(\mathbf{k N})$ & $N / N_{f i, R d}$ & $N_{f i, R d}(\mathrm{kN})$ & $N / N_{f i, R d}$ \\
\hline F-RE-50 & 198.96 & 69.32 & 2.87 & 55.29 & 3.60 \\
\hline F-RE-20 & 281.84 & 119.39 & 2.36 & 93.13 & 3.03 \\
\hline F-RE-50 & 204.51 & 79.16 & 2.58 & 62.29 & 3.28 \\
\hline \multirow[t]{3}{*}{ F-RE-20 } & 287.94 & 125.36 & 2.30 & 101.48 & 2.84 \\
\hline & & Mean & 2.53 & Mean & 3.19 \\
\hline & & Std. dev. & 0.26 & Std. dev. & 0.33 \\
\hline
\end{tabular}




\section{LIST OF FIGURE CAPTIONS}

Fig. 1. Cross-sectional dimensions: a) unreinforced columns; b) reinforced columns

Fig. 2. Three-dimensional view of the test setup: a) room temperature test; b) fire test

Fig. 3. Effect of the load eccentricity for room temperature tests

Fig. 4. a) Schematic view of the column inside the furnace; b) thermocouple location at section A-A'; c) thermocouple location at section B-B'

Fig. 5. Column after failure: a) general view; b) detail of the top end; c) detail of the bottom end

Fig. 6. Effect of the load eccentricity on the fire tests: a) unreinforced columns; b) reinforced columns

Fig. 7. Comparison between calculated buckling load and test load, with EC4 method and proposed method

\section{LIST OF TABLE CAPTIONS}

Table 1. Characteristics of the column specimens

Table 2. Summary of the results obtained with EC4 method (room temperature tests)

Table 3. Summary of the results obtained with EC4 method (fire tests)

Table 4. Summary of the results obtained with the proposed method (fire tests) 